\title{
Preparation of an antitumor and antivirus agent: chemical modification of $\alpha-M M C$ and MAP30 from Momordica Charantia L. with covalent conjugation of polyethyelene glycol
}

\author{
This article was published in the following Dove Press journal: \\ International Journal of Nanomedicine \\ 20 June 2012 \\ Number of times this article has been viewed
}

\author{
Yao Meng ${ }^{1,2}$ \\ Shuangfeng Liu' \\ Juan $\mathrm{Li}^{3}$ \\ Yanfa Meng ${ }^{3}$ \\ Xiaojun Zhao ${ }^{2,4}$
}

'School of Medical Laboratory Science, Chengdu Medical College, Chengdu, China; ${ }^{2}$ West China Hospital Laboratory of Nanomedicine and Institute for Nanobiomedical Technology and Membrane Biology, Sichuan University, Chengdu, China; ${ }^{3}$ Key Laboratory of Bio-resources and Eco-environment Ministry of Education/Animal Disease Prevention and Food Safety Key Laboratory of Sichuan Province, College of Life Science, Sichuan University, Chengdu, China; ${ }^{4}$ Center for Biomedical Engineering, Massachusetts Institute of Technology, Cambridge, MA, USA

Correspondence: Xiaojun Zhao West China Hospital Laboratory of Nanomedicine and Institute for Nanobiomedical Technology and Membrane Biology, Sichuan University, Ke Yuan 4th Street, Chengdu 61004I, China

Tel +862885164072

Fax +862885164072

Email xiaojunz@mit.edu

Yanfa Meng

Key Laboratory of Bio-resources and Eco-environment Ministry of Education, College of Life Science, Sichuan University, Chengdu 610064, China

Tel +8628 8547 I54 I

Fax +8628 854I257।

Email yfmeng0902@scu.edu.cn
Background: Alpha-momorcharin ( $\alpha$-MMC) and momordica anti-HIV protein (MAP30) derived from Momordica charantia $L$. have been confirmed to possess antitumor and antivirus activities due to their RNA- $N$-glycosidase activity. However, strong immunogenicity and short plasma half-life limit their clinical application. To solve this problem, the two proteins were modified with (mPEG) 2 -Lys-NHS (20 kDa).

Methodology/principal findings: In this article, a novel purification strategy for the two main type I ribosome-inactivating proteins (RIPs), $\alpha$-MMC and MAP30, was successfully developed for laboratory-scale preparation. Using this dramatic method, $200 \mathrm{mg}$ of $\alpha$-MMC and about $120 \mathrm{mg}$ of MAP30 was obtained in only one purification process from $200 \mathrm{~g}$ of Momordica charantia seeds. The homogeneity and some other properties of the two proteins were assessed by gradient SDS-PAGE, electrospray ionization quadruple mass spectrometry, and $N$-terminal sequence analysis as well as Western blot. Two polyethylene glycol (PEG)ylated proteins were synthesized and purified. Homogeneous mono-, di-, or tri-PEGylated proteins were characterized by matrix-assisted laser desorption ionization-time of flight mass spectrometry. The analysis of antitumor and antivirus activities indicated that the serial PEGylated RIPs preserved moderate activities on JAR choriocarcinoma cells and herpes simplex virus-1. Furthermore, both PEGylated proteins showed about $60 \%-70 \%$ antitumor and antivirus activities, and at the same time decreased $50 \%-70 \%$ immunogenicity when compared with their unmodified counterparts.

Conclusion/significance: $\alpha-M M C$ and MAP30 obtained from this novel purification strategy can meet the requirement of a large amount of samples for research. Their chemical modification can solve the problem of strong immunogenicity and meanwhile preserve moderate activities. All these findings suggest the potential application of PEGylated $\alpha$-MMC and PEGylated MAP30 as antitumor and antivirus agents. According to these results, PEGylated RIPs can be constructed with nanomaterials to be a targeting drug that can further decrease immunogenicity and side effects. Through nanotechnology we can make them low-release drugs, which can further prolong their half-life period in the human body.

Keywords: ribosome-inactivating proteins, alpha-momorcharin, momordica anti-HIV protein, antitumor, antivirus, (mPEG) $)_{2}$-Lys-NHS (20 kDa), immunogenicity

\section{Introduction}

Momordica charantia L. (MC), a Momordica Linn. genus of the family Cucurbitaceae and commonly known as bitter melon, is a traditional medicine plant indigenous to China. ${ }^{1}$ The fruit and seed extracts from MC have been used in China for centuries for antivirus, antitumor, and immunopotentiating agent purposes. ${ }^{2}$ In recent years, 
several ribosome-inactivating proteins (RIPs), including momordica anti-HIV protein (MAP30) and $\alpha$-momorcharin (MMC), $\beta$-MMC, and $\gamma$-MMC, a group of which belong to the family of single-chain RIPs, were found to have the ability to inhibit protein biosynthesis in tumor cells by catalytic inactivation of the $60 \mathrm{~S}$ ribosomal subunit. ${ }^{3,4}$ These proteins were also found to be able to inhibit the multiplication of herpes simplex virus-1 (HSV-1), ${ }^{4,5}$ poliovirus I in Hep2 cells, ${ }^{6}$ and acquired human immunodeficiency virus type-1 (HIV-1). ${ }^{7}$ However, the strong immunogenicity, allergic reaction, and short half-life of these proteins have been considered the major barriers for their application as therapeutic agents in vivo. ${ }^{89}$ In recent years, researchers have shifted their focus to other technologies. An established technology, polyethylene glycol (PEG) conjugation (PEGylation), can bestow on proteins several benefits, such as increasing plasma half-life, decreasing toxicity, and reducing immunogenicity and antigenicity. ${ }^{9,10}$ The Food and Drug Administration has approved the PEGylated forms of the therapeutic proteins such as uricase, erythropoietin, granulocyte-colony stimulating factor, interferon, adenosine deaminase, asparaginase, and a growth hormone antagonist. Another technology is nanotechnology, which uses nanomaterials for packing potential therapeutic proteins to extend the half-life period or to make them targeting drugs.

$\alpha$-MMC and MAP30 as potential therapeutic proteins possess biological activities such as inhibiting protein biosynthesis (ribosome inactivation), ${ }^{11}$ antitumor, antivirus, and, especially, anti-HIV replication. ${ }^{7,12,13}$ However, as foreign proteins are like other potential therapeutic proteins, poor biocompatibility limits their further development and application. To overcome these problems, in this study we first purified the two main proteins from bitter melon seeds and carried out their PEGylation using a branched $20 \mathrm{kDa}$ (mPEG) $)_{2}$-Lys-NHS directed specifically to lysil $\varepsilon$-amino groups. Homogeneous one-mer, two-mer, and three-mer PEG-RIPs were then identified by matrix-assisted laser desorption ionization-time of flight mass spectrometry (MALDI-TOF-MS). Not only was their immunogenicity in vivo remarkably decreased but also, importantly, their antitumor and antivirus activities in vitro were moderately influenced when compared with the un-PEGylated counterparts. This work is just the beginning step towards them being used clinically. The application of PEGylation and nanotechnolgy may indicate that the potential application of both $\alpha$-MMC and MAP30 can be developed for antitumor and antivirus agents in the future.

\section{Materials and methods Materials}

Bitter melon seeds were obtained from the Institute of Agricultural Science and Technique of Sichuan Province, China. Matrices for electrophoresis were products of SigmaAldrich (St Louis, MO) and Bio-Rad Laboratories (Hercules, CA). SP-Sepharose FF, Sephacryl S-100, Macro-Cap-SP, and ampholyte were purchased from Amersham Pharmacia Biotech (Piscataway, NJ). (mPEG) $)_{2}$-Lys-NHS (20 kDa) was obtained from Shearwater Polymers (Huntsville, AL). Dulbecco's Modified Eagle's Medium (DMEM) and fetal bovine serum used in cell culture were from Gibco BRL (Grand Island, NE). pUC18 DNA was purchased from TAKARA (Dalian, China). Nitrocellulose (NC) membrane was obtained from Bio-Rad Laboratories. Sheep-antimouse Ab-linked to alkaline phosphatase was purchased from Sigma-Aldrich. JAR choriocarcinoma cells were purchased from the Cell Bank of Shanghai Institute of Cell Biology (Shanghai, China).

\section{Purification of $\alpha-M M C$ and MAP30}

All steps tried either alone or in combination within the process of purification were carried out at $4-6^{\circ} \mathrm{C}$ unless specifically stated. Firstly, the powder from fresh bitter melon seeds was extracted in $0.15 \mathrm{M} \mathrm{NaCl}$ solution and then the $\mathrm{pH}$ of the solution was adjusted to 4.0. After simple centrifugation, the supernatant was neutralized and fractionated by $30 \%-65 \%$ ammonium sulfate. The precipitate was dialyzed against the pH 6.3, 0.05 M phosphate buffer. Secondly, the sample was applied onto a SP-Sepharose FF column and eluted with pH 6.3, $0.05 \mathrm{M}$ phosphate buffer containing $0.15 \mathrm{M} \mathrm{NaCl}$. The elution peak containing $30 \mathrm{kDa}$ protein was collected. Thirdly, the portion was loaded onto a Sephacryl S-100 column and the elution peak with $30 \mathrm{kDa}$ protein was pooled. Finally, the sample was applied onto a Macro-Cap-SP column. A linear gradient of $0-0.15 \mathrm{M} \mathrm{NaCl}$ in $\mathrm{pH} 7.0,20 \mathrm{mM}$ sodium phosphate buffer eluted the column and two peaks with $30 \mathrm{kDa}$ proteins were respectively collected.

\section{Determination of protein concentration}

Protein concentration was determined by the method of Lowry et $\mathrm{al}^{14}$ or ultraviolet spectrometry at $280 \mathrm{~nm}$ using bovine serum albumin (BSA) as standard.

\section{Identification of $\alpha-M M C$ and MAP30 SDS-PAGE \\ SDS-PAGE was performed according to Laemmli. ${ }^{15}$}


Assay of the amino-terminal sequence ESI-QUAD-MS and MALDI-TOF-MS

Both the amino-terminal sequences MALDI-TOF-MS and electrospray ionization quadruple mass spectrometry (ESI-QUAD-MS) were consigned to the Beijing Proteome Research Center of China to complete the analysis.

\section{Western blotting analysis}

Briefly, $\alpha$-MMC was separated on SDS-PAGE and then transferred to an $\mathrm{NC}$ membrane. Nonspecific binding was blocked and washed by placing the membrane in a solution of BSA. NC membrane was incubated with a mouse anti- $\alpha-M M C M c A b$ and was exposed to a sheep-antimouse $\mathrm{Ab}$ linked to alkaline phosphatase. After adding BCIP (5-bromo-4-chloro-3-indolyl phosphate), the colored bands were visualized and photographed. ${ }^{16}$ In the analysis of MAP30, NC membrane was incubated with a diluted solution of rat anti-MAP30 PcAb under gentle agitation. Other conditions were the same with $\alpha$-MMC.

\section{Chemical synthesis and identification of PEGylated $\alpha-M M C$ and PEGylated MAP30}

In general, PEGylated $\alpha-M M C$ and PEGylated MAP 30 can be obtained in the following optimal conditions: $10 \mathrm{mg} / \mathrm{mL}$ of $\alpha$-MMC or MAP30 reacted with (mPEG) ${ }_{2}$-Lys-NHS (mass ratio of PEG:RIP was 2:1) in $\mathrm{pH} 8.5,100 \mathrm{mM}$ borate buffer at room temperature for 30 minutes. The reaction mixture was applied with Sephacryl S-100 column. The PEGylated conjugates can be collected and assessed by gradient SDSPAGE and MALDI-TOF-MS.

\section{Topological inactivation activity}

Topological inactivation activity was according to a previously described method. ${ }^{17}$

\section{Antitumor activity in vitro}

JAR choriocarcinoma cells were maintained in an incubator supplied with a humidified atmosphere of $5 \% \mathrm{CO}_{2}$ at $37^{\circ} \mathrm{C}$. The culture medium was DMEM containing $20 \mathrm{mM}$ HEPES and $10 \%$ fetal bovine serum. The cell viability and proliferation were determined by quantitative 3-(4,5dimethylthiozol-2-yl)-2,5- diphenyltetrazolium bromide (MTT). A total of $3 \times 10^{4}$ cells $/ \mathrm{mL}$ were applied into 96-well microtiter plates at $100 \mu \mathrm{L}$ per well and exposed to PEGylated $\alpha$-MMC, PEGylated MAP30, and un-PEGylated counterparts of $0.012,0.06,0.3$, and $1.5 \mathrm{mg} / \mathrm{mL}$ at 24,48 , and 72 hours. Cells without drugs were used as controls. Each concentration was tested in quadruplicate. The determination procedure was carried out according to the previous description. ${ }^{18}$ The optical density (OD) at $570 \mathrm{~nm}$ was measured using an ELISA plate reader $(\mathrm{EL} \times 800$, BIO-TEK, Atlanta, GA). Cell viability and proliferation were observed together with controls.

\section{The inhibitory effect of PEGylated RIPs on herpes simplex virus- I}

VERO cells were cultured to logarithmic growth phase in $10 \mathrm{~mL}$ DMEM containing $10 \%(\mathrm{v} / \mathrm{v})$ fetal bovine serum, $100 \mu \mathrm{g} / \mathrm{mL}$ penicillin, and $100 \mathrm{U} / \mathrm{mL}$ streptomycin. After removing medium, cells were substituted to $5 \mathrm{~mL}$ of the above medium and infected with $100 \mu \mathrm{L}$ of herpes simplex virus-1 (HSV-1) for 1.5 hours. Then, $5 \mathrm{~mL}$ maintenance medium containing $2 \%(\mathrm{v} / \mathrm{v})$ fetal bovine serum, $100 \mu \mathrm{g} / \mathrm{mL}$ penicillin, and $100 \mathrm{U} / \mathrm{mL}$ streptomycin was added and cells were continually cultured for about 1-2 days when over $80 \%$ cells appeared with cytopathic effect (CPE). The infected supernatant was collected for testing of virus titers.

\section{Determination of virus titer}

VERO cells of $1 \times 10^{5}$ cells $/ \mathrm{mL}$ were applied $100 \mu \mathrm{L}$ per well to 96-well microtiter plates and cultured for 24 hours. After discarding medium, $100 \mu \mathrm{L}$ of infected supernatant, which was $10^{-1}$ to $10^{-10}$ diluted with medium, was added to each well (quadruplicate) until CPE did not increase. TCID $_{50}$ (50 percent tissue culture infective dose) was calculated according to Reed and Muench. ${ }^{19,20}$

\section{Measurement of cytotoxicity}

The cytotoxicity of PEGylated $\alpha-M M C$ and PEGylated MAP30 was evaluated by the quantitative MTT test. ${ }^{21}$ A total of $1 \times 10^{5}$ VERO cells $/ \mathrm{mL}$ was applied to 96 -well microtiter plates at $100 \mu \mathrm{L}$ per well and was exposed to un-PEGylated proteins and PEGylated-proteins at $3.3 \mu \mathrm{mol} \cdot \mathrm{L}^{-1} \sim 3.3 \mathrm{nmol} \cdot \mathrm{L}^{-1}\left(100 \mathrm{mg} \cdot \mathrm{L}^{-1} \sim 0.1 \mathrm{mg} \cdot \mathrm{L}^{-1}\right)$ and acyclovir (ACV) at $10 \mu \mathrm{mol} \cdot \mathrm{L}^{-1} \sim 0.01 \mu \mathrm{mol} \cdot \mathrm{L}^{-1}$ for 48 hours as well as cells without drugs as control. Each concentration was tested in quadruplicate. The determination procedure was carried out according to the previous description. ${ }^{18}$ The OD at $490 \mathrm{~nm}$ was measured using ELISA:

$$
\text { Cell viability }(\%)=\frac{\mathrm{OD}_{490 \text { sample }}}{\mathrm{OD}_{490 \text { sample }}} \times 100 \%
$$


Table I Summarization of purification of alpha-momorcharin ( $\alpha-M M C)$ and momordica anti-HIV protein (MAP30) from 200 g of bitter melon seeds

\begin{tabular}{|c|c|c|c|c|c|c|c|c|}
\hline \multirow{2}{*}{$\begin{array}{l}\text { Steps } \\
\text { Extract-free cells }\end{array}$} & \multicolumn{2}{|c|}{ Total volume $(\mathrm{mL})$} & \multicolumn{2}{|c|}{ Protein content $(\mathrm{mg} / \mathrm{mL})$} & \multicolumn{2}{|c|}{ Total protein (mg) } & \multicolumn{2}{|l|}{ Field (\%) } \\
\hline & 800 & & 15.0 & & 12,000 & & 100 & \\
\hline AS precipitation & 100 & & 37.5 & & 3750 & & 32.0 & \\
\hline SP Sepharose FF & 360 & & 2.3 & & 828 & & 6.9 & \\
\hline Sephacryl S-100 & 110 & & 4.5 & & 495 & & 4.1 & \\
\hline \multirow[t]{2}{*}{ Macro-Cap-SP } & $\alpha-M M C$ & MAP30 & $\alpha-M M C$ & MAP30 & $\alpha-M M C$ & MAP30 & $\alpha-M M C$ & MAP30 \\
\hline & 40 & 35 & 5.3 & 3.5 & 200 & 120 & 1.7 & 1.0 \\
\hline
\end{tabular}

Notes: Values reported are an average value of five preparations. The data from both crude extraction and precipitation with ammonium sulfate were obtained by the method of Lowry et al; ${ }^{14}$ other data were assayed at $280 \mathrm{~nm}$.

\section{Inhibition of proteins on HSV-I antigen secretion}

A total of $1 \times 10^{5} \mathrm{VERO}$ cells/mL were seeded into 24 -well plates at $1 \mathrm{~mL} /$ well and then incubated with $5 \% \mathrm{CO}_{2}$ at $37^{\circ} \mathrm{C}$ for 24 hours. After abandoning the supernatant, $300 \mu \mathrm{L}$ HSV-1 stock solution with $100 \mathrm{TCID}_{50} / \mathrm{mL}$ was added to each well and incubated for 1.5 hours. Then, $100 \mu \mathrm{L}$ of culture medium containing proteins (concentration was mentioned previously in the cytotoxity method) was added to each well and negative and positive cell control established. After incubation for 48 hours, HSV-1 antigen in culture supernatant was tested by human HSV-1 antigen 1 (HSV-1 AG1) enzymelinked immunosorbent assay kit with indirect ELISA:

Inhibition rate $(\%)=\frac{O D_{\text {positive control }}-\mathrm{OD}_{\text {sample }}}{\mathrm{OD}_{\text {positive control }}-\mathrm{OD}_{\text {negative control }}} \times 100 \%$

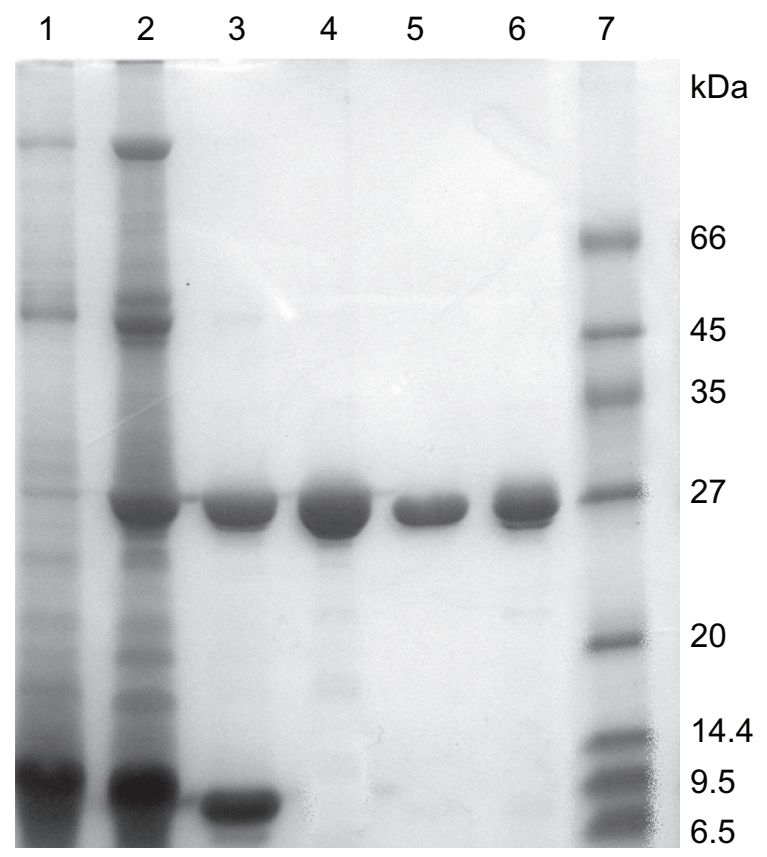

Figure I SDS-PAGE of extracts and eluates from different purification steps. Lane I: crude extract; Lane 2: dialytic sample after AS precipitation; Lane 3: eluate from SP-Sepharose FF chromatography; Lane 4: eluate from gel filtration chromatography; Lane 5: $\alpha-M M C$ from Macro-Cap-SP chromatography; Lane 6: MAP30 from MacroCap-SP chromatography; Lane7: LMW calibration kit.
The analysis of virus inactivation

VERO cells infected with HSV-1 were added with $20 \mu \mathrm{L}$ $(5 \mathrm{mg} / \mathrm{mL})$ of MTT to each well and incubated at $37^{\circ} \mathrm{C}$ for 4 hours. Then, $150 \mu \mathrm{L}$ of DMSO was added to each well. The $\mathrm{OD}_{490}$ was read by a microplate spectrophotometer. The percentage of inhibition was calculated by the formula described under the heading "Measurement of cytotoxicity."

\section{Immunogenicity of PEGylated $\alpha-M M C$ and PEGylated MAP30}

Fifty Sprague Dawley rats were randomly classified into control, $\alpha$-MMC, PEGylated $\alpha$-MMC, MAP30, and PEGylated MAP30 groups of ten each. The rats in the control group were subcutaneously injected with saline solution, and the RIP and PEGylated RIP groups were emulsified in Freund's complete adjuvant at a dose of $1.42 \mathrm{mg} / \mathrm{kg}$ at the infection frequency of 3 days for 17 days. Blood samples were collected from the capillary vessel in rats' eyes and separated sera were stored at $-20^{\circ} \mathrm{C}$. Antigen-specific serum IgG levels were measured by ELISA. Briefly, 96-well plates were coated with $100 \mu \mathrm{L}$ of $30 \mu \mathrm{g} / \mathrm{mL}$ purified antigen (RIPs and PEG-RIPs) in 0.05 M carbonate-coating buffer,

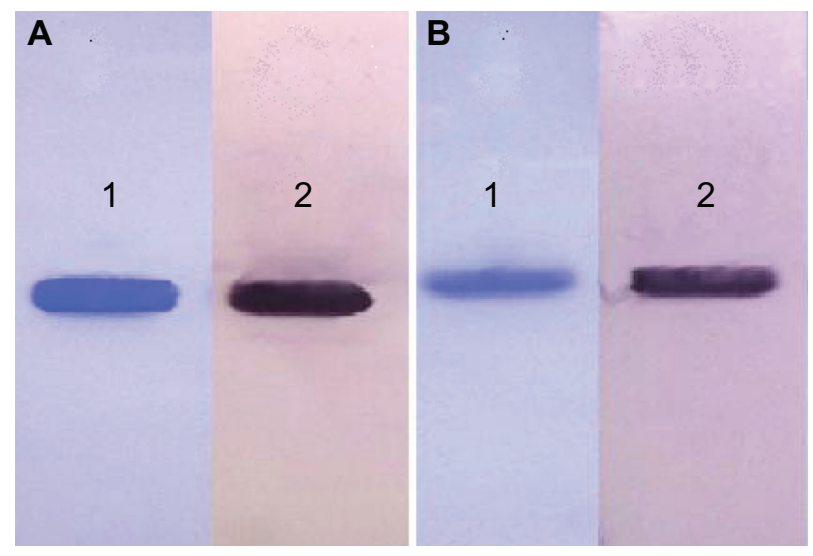

Figure 2 Western blot analysis of $\alpha-M M C$ and MAP30. (A) Lane I: reduced SDSPAGE of $\alpha-M M C$; Lane 2: western blot profile of $\alpha-M M C$. (B) Lane I: reduced SDS-PAGE of MAP30; Lane 2: western blot profile of MAP30. 

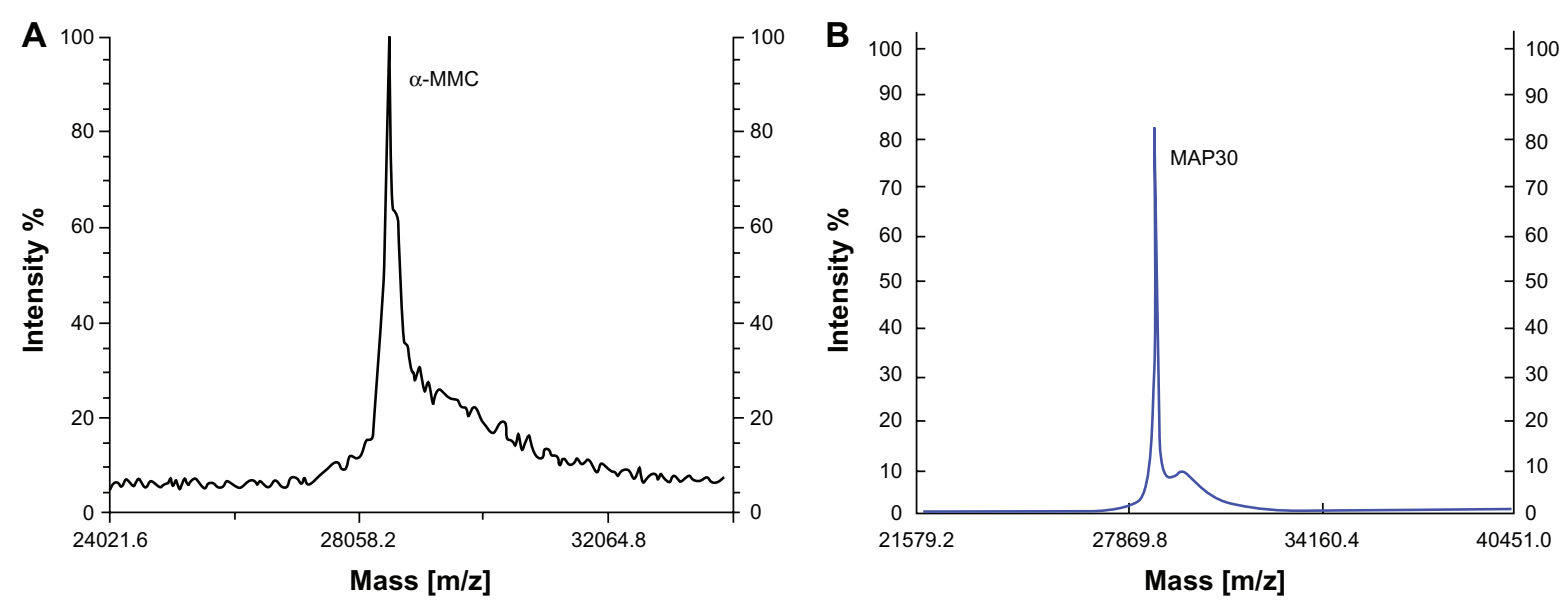

Figure 3 MALDI-TOF-MS analyses of both $\alpha-M M C$ and MAP30. (A) MALDI-TOF-MS profile of $\alpha-M M C$. The average MW of $\alpha-M M C$ was 2855 I.6 Da (B) MALDI-TOF-MS profile of MAP30. The average MW of MAP30 was $29072.0 \mathrm{Da}$.

$\mathrm{pH}$ 9.6, and incubated at $4^{\circ} \mathrm{C}$. After washing, $300 \mu \mathrm{L}$ of PBS containing 3\% BSA, pH 7.4, was added to each well, followed by 2.5 hours of incubation at $37^{\circ} \mathrm{C}$. Diluted sera (1:16) were added $(100 \mu \mathrm{L} /$ well) and followed by 2.5 hours of incubation at $37^{\circ} \mathrm{C}$. Wells were then washed in PBS washing buffer, $\mathrm{pH} 7.4$, containing $0.05 \%$ Tween-20, and incubated with peroxidase-conjugated AffiniPure goat antimouse $\operatorname{IgG}(1: 16000)$ at $37^{\circ} \mathrm{C}$ for 2.5 hours. Then, the plate was washed five times in PBS followed by the addition of $100 \mu \mathrm{L} /$ well tetramethyl benzidine (Sigma-Aldrich) as a substrate for horseradish peroxidase. The reactions were allowed to develop at $37^{\circ} \mathrm{C}$ for 15 minutes. Finally, $50 \mu \mathrm{L}$ of $2 \mathrm{M}$ sulfuric acid was added to stop the reaction. The absorbance was measured with a plate reader (Model 680, Bio-Rad Laboratories) at $450 \mathrm{~nm}$.

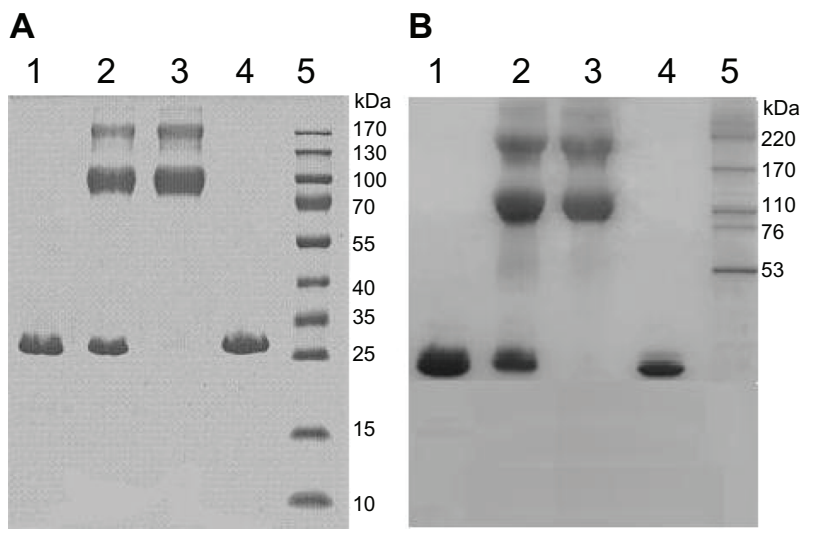

Figure 4 Gradient SDS-PAGE of both PEGylated $\alpha-M M C$ and PEGylated MAP30 conjugates. (A) Lane I: $\alpha-M M C$ as a control; Lane 2: mixture of $\alpha-M M C$ and $\alpha-M M C$ PEG conjugate; Lane 3: purified $\alpha$-MMC-PEG conjugate; Lane 4: unmodified $\alpha$-MMC; Lane 5: HMW calibration kit. (B) Lane I: MAP30 as a control; Lane 2: mixture of MAP30 and MAP30-PEG conjugate; Lane 3: purified MAP30-PEG conjugate; Lane 4: unmodified MAP30; Lane 5: HMW calibration kit.

\section{Statistical analysis}

SPSS statistical software (SPSS, Inc, Chicago, IL) was used for analysis. $P<0.05$ was considered statistically significant.

\section{Results and discussion Purification and identification of $\alpha-M M C$ and MAP30}

Purification of $\alpha$-MMC and MAP30 was performed by applying 30\%-65\% ammonium sulfate precipitation, acidification, SP-Sepharose FF, Sephacryl S-100, and Macro-Cap-SP chromatography. In conclusion, $200 \mathrm{mg}$ of $\alpha$-MMC and $120 \mathrm{mg}$ of MAP30 with the recoveries of $1.7 \%$ and $1.0 \%$, respectively, was obtained from $200 \mathrm{~g}$ starting material seeds. The procedure of purification is summarized in Table 1. Both $\alpha$-MMC and MAP30 were assessed by SDS-PAGE (Figure 1) and Western blotting (Figure 2). By using the Compute pI/ Mw program from ExPASy Proteomics Server (http://www. expasy.org), the theoretical $\mathrm{pI}$ of $\alpha-\mathrm{MMC}$ is 9.32 and MAP30 is 8.86. And this is coincident with the result of IEF analyses of these two proteins. ESI-QUAD-MS was used to further identify the two proteins, and sequences were analyzed using the BLAST program (http://www.expasy.org/tools/blast/), which demonstrated that they are $\alpha$-MMC (Swiss Prot accession number: P16094, peptides are YLLMHLFNYDGK) and MAP30 (Swiss-Prot accession number: P24817, peptides are ESPPEAYNILFK). MALDI-TOF-MS was used to determine the accurate molecular weight of $\alpha$-MMC and MAP30. The results showed that the molecular weights were $28551.6 \mathrm{Da}$ and 29072.0 Da, respectively (Figure 3), while the theoretical molecular weight was 27368.36 Da and 29600.74 Da (http:// www.expasy.org). Edman degradation indicated that the 

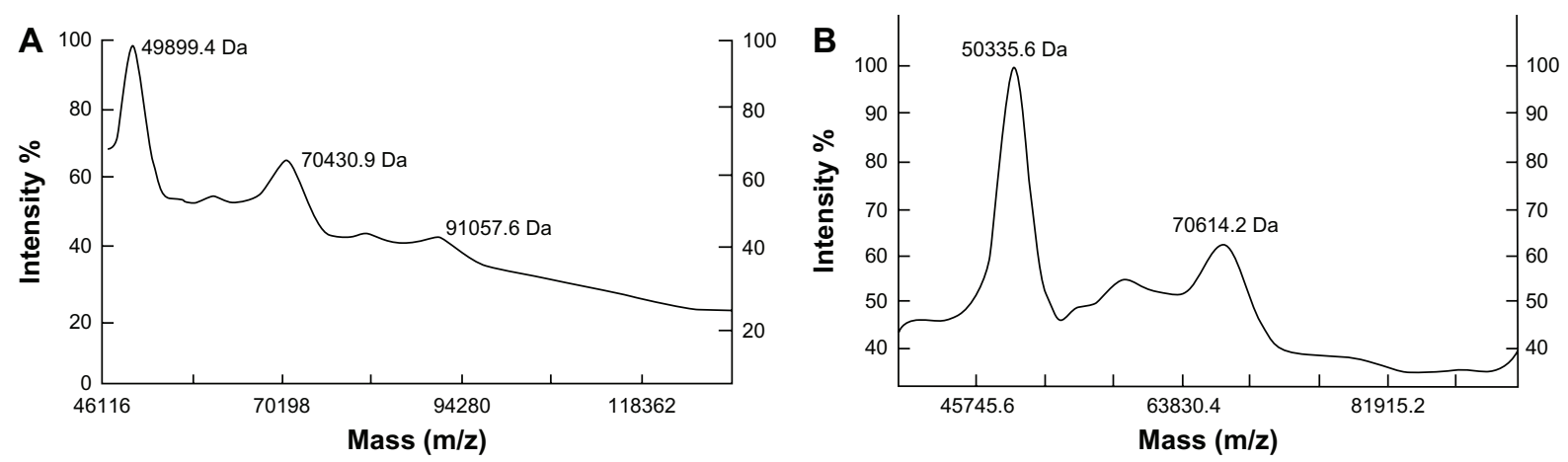

Figure 5 MALDI-TOF-MS analysis of both PEGylated $\alpha-M M C$ and PEGylated MAP30 conjugates. (A) The (mPEG) 2 -Lys-NHS was around 20 kDa and the PEG conjugates were observed at 49899.4 Da, 70430.9 Da and 91057.6 Da, reflecting I, 2 or 3 PEG-bound chains per $\alpha-M M C$ molecule. (B) The (mPEG) ${ }_{2}$-Lys-NHS was around 20 kDa and the PEG conjugates were observed at $50335.6 \mathrm{Da}$ and 706I4.2 Da, reflecting I or 2 PEG-bound chains per MAP30 molecule.

$N$-terminal sequence of the purified proteins, N-Asp-Val-SerPhe-Arg and N-Asp-Val-Asn-Phe-Asp, was consistent with theoretical sequences of both $\alpha$-MMC and MAP30.

\section{Purification and identification of PEGylated $\alpha-M M C$ and PEGylated MAP30}

Through optimized PEGylation reaction, a high total PEGylation ratio can be obtained (about 60\%-70\%). The gradient SDS-PAGE monitoring (Figure 4) showed that the un-PEGylated counterparts from the reaction mixture were successfully removed by Sephacryl S-100 chromatography or Superdex 75 chromatography. In the MALDI-TOF-MS analysis (Figure 5), one-mer, two-mer, and three-mer PEGylated isomers with 49899.4 Da, 70430.9 Da, and 91057.6 Da (the molar ratios of $1: 1,2: 1$, and $3: 1$ of (mPEG) $)_{2}$-LysNHS: $\alpha-M M C$ ) were detected from $\alpha-M M C-P E G$ conjugates.

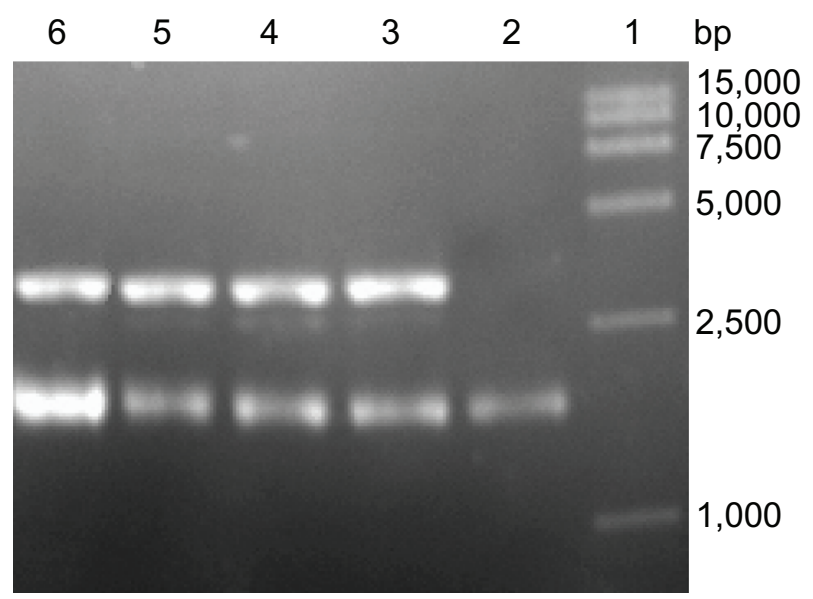

Figure 6 Topological inactivation activities. Lane I: DNA marker; Lane 2: pUCI8 DNA as a control; Lane 3 and 4: pUCI 8 DNA was incubated with $\alpha-M M C$, PEG- $\alpha-$ MMC; Lane 5 and 6: pUCI8 DNA was incubated with MAP30, PEG-MAP30.
Meanwhile, one-mer and two-mer PEGylated isomers with 50335.6 Da and 70614.2 Da (the molar ratios of 1:1 and 2:1 of (mPEG) $)_{2}$-Lys-NHS: MAP30) were found from MAP30PEG conjugates.

\section{Topological inactivation activity}

To demonstrate their topological inactivation activity, supercoiled DNA (pUC18) was incubated with PEGylated RIPs and un-PEGylated counterparts. In suitable enzymatic digestion conditions, all of the experiment samples cleaved the supercoiled double-stranded DNA to produce nicked circular or linear DNA. As shown in Figure 6, all of them exhibited DNase-like activity.

\section{Effects of PEGylated $\alpha-M M C$ and PEGylated MAP30 on proliferation of JAR cells}

To investigate the effect of PEGylated $\alpha$-MMC and PEGylated MAP30 on cell viability and proliferation, JAR cells were seeded on 96-well plates and were treated with increasing concentrations of PEGylated RIPs and un-PEGylated counterparts for 72 hours (Figure 7A) and for different times at $1.5 \mathrm{mg} / \mathrm{mL}$ (Figure $7 \mathrm{~B}$ ). Statistical analysis revealed that the concentrations of $1.5,0.3$, and $0.06 \mathrm{mg} / \mathrm{mL}$ started to significantly reduce the proliferation of cells after 48 and 72 hours of incubation. The analyses with the result of Figure $7 \mathrm{~A}$ exhibited that native $\alpha$-MMC allowed an approximately $21 \%$ decrease compared with the PEGylated $\alpha$-MMC and $25 \%$ of MAP30 with the PEGylated MAP30 at the highest tested concentration. This can indirectly demonstrate a dose- and time-dependent inhibition to the growth of JAR choriocarcinoma cells. The result in the analysis of Figure 7B displayed that the growth of cells was 
A

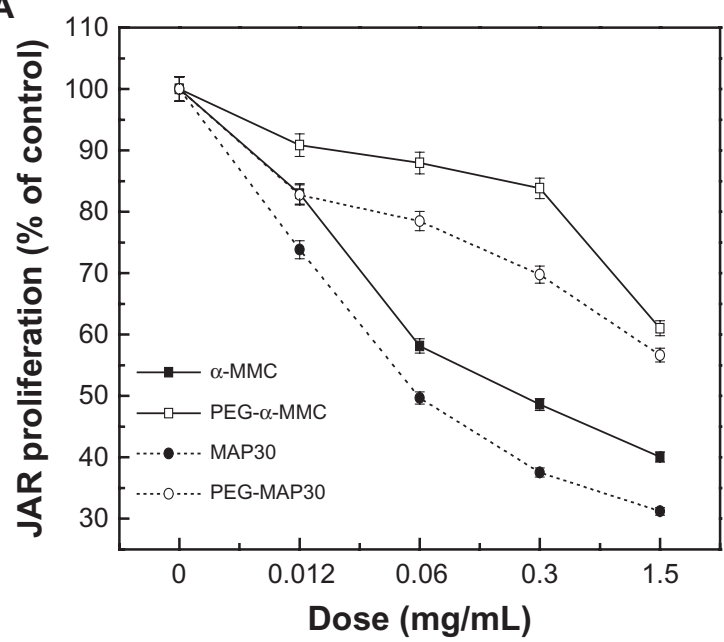

B

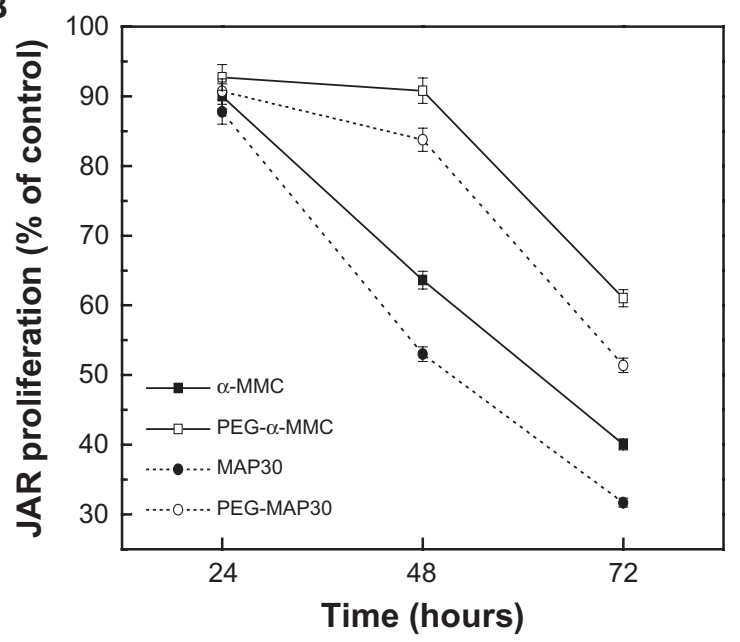

Figure 7 Inhibitory effects of $\alpha$-MMC/MAP30 and PEG- $\alpha$-MMC/MAP30 on the proliferation of human choriocarcinoma JAR cells. JAR cells were treated with increasing concentrations for 72 hours. (A) and for various time points at $1.5 \mathrm{mg} / \mathrm{mL}$. (B) of native or PEGylated $\alpha$-MMC/MAP30 as indicated. Note: Each data point represents the average of three independent experiments performed in quadruplicate.

not prominent after 24 hours of treatment, but continued incubation for 48 or 72 hours with the proteins enhanced the cytotoxicity on cells.

$\alpha$-MMC and PEGylated $\alpha$-MMC induced alterations in the morphology of JAR cells (Figure 8). After processing for 72 hours, untreated JAR cells extended and flattened (Figure 8A), while the treated groups showed fewer cells and abnormal shapes such as shrinkage, blebbing, and loss of membrane asymmetry, indicating the cytotoxic effect of $\alpha$-MMC and its modifier on JAR cells. In particular, $\alpha$-MMC-treated groups showed extremely obvious morphological changes (Figure 8C and D). MAP30 and PEGylated MAP30 also showed a similar cytotoxic effect to JAR cells.

\section{The inhibitory effect of PEGylated $\alpha-M M C$ and PEGylated MAP30 on HSV-I}

$\mathrm{TCID}_{50}$ was calculated using the method of Reed and Muench, ${ }^{19}$ and the emergence of CPE was used as a positive sign. The CPE of each dilution of HSV-1 cytopathic was tabulated as in Table 2. Measurement of cytotoxicity was designed to establish appropriate dose range for the research of inhibitory effect of proteins on HSV-1 to VERO cells. The result (Figure 9) reflected the effects of different concentrations of test proteins on cell viability of VERO cells and showed that $\alpha$-MMC/MAP30, PEG- $\alpha-M M C / M A P 30$, and ACV had no significant inhibition on VERO cells in the tested concentration range. The cell viability maintained above $97 \%$ from $0.003-0.03 \mu \mathrm{mol} \cdot \mathrm{L}^{-1}$ and $85 \%$ from $0.3-3.3$
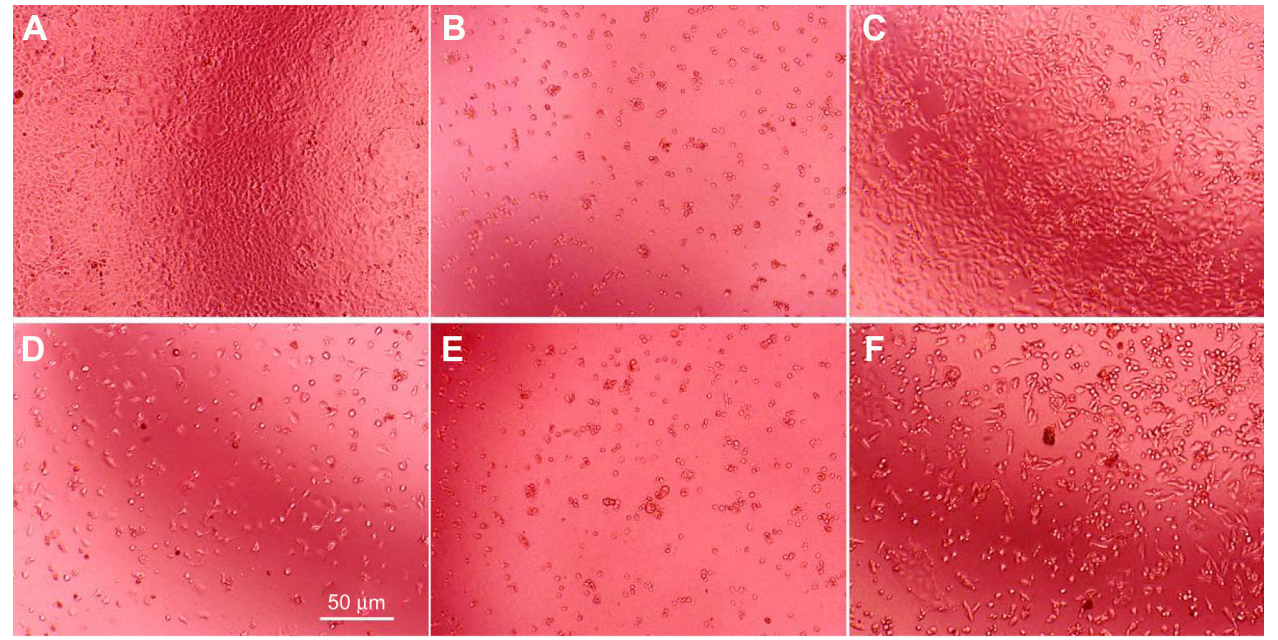

Figure 8 Morphological differences in JAR cells for 72 hours culture photographed by phase contrast microscopy. JAR cells treated without drugs (A), with I5 $\mu g / m L$ 5-fluorouracil (B), with 0.3 (C) and $1.5 \mathrm{mg} / \mathrm{mL} \alpha-M M C$ (D) and with 0.3 (E) and $1.5 \mathrm{mg} / \mathrm{mL}$ PEG- $\alpha-M M C$. (F) The white bar presents $50 \mu \mathrm{m}$. 
Table 2 Herpes simplex virus-I-induced cytopathic effect (CPE) of VERO cell $\left(50 \%\right.$ tissue culture infective dose $\left(\mathrm{TCID}_{50}\right)=$ antilog $\left.\left.[(55.6-50) / 55.6-20) \times(-1)+\left(\lg \mid 0^{-5}\right)\right]=10^{-5.2} / 0.1 \mathrm{~mL}=10^{-6.2} / \mathrm{mL}\right)$

\begin{tabular}{|c|c|c|c|c|}
\hline \multirow{2}{*}{$\begin{array}{l}\text { Virus } \\
\text { ratio } \\
\text { dilution }\end{array}$} & \multicolumn{2}{|c|}{$\begin{array}{l}\text { CPE appearing } \\
\text { in cell holes }\end{array}$} & \multirow{2}{*}{$\begin{array}{l}\text { Total } \\
\text { number } \\
\text { of cell holes }\end{array}$} & \multirow{2}{*}{$\begin{array}{l}\text { CPE } \\
\text { appearing in } \\
\text { cell holes (\%) }\end{array}$} \\
\hline & Positive & Negative & & \\
\hline-3 & 16 & 0 & 16 & 100 \\
\hline-4 & 10 & I & 11 & 90.9 \\
\hline-5 & 5 & 4 & 9 & 55.6 \\
\hline-6 & 2 & 8 & 10 & 20 \\
\hline-7 & 0 & 14 & 14 & 0 \\
\hline-8 & 0 & 20 & 20 & 0 \\
\hline
\end{tabular}

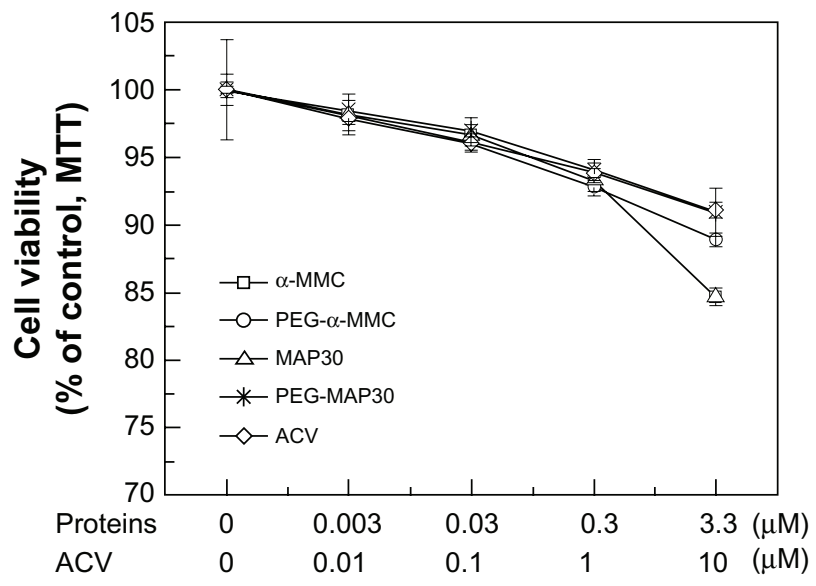

Figure 9 Different concentrations of proteins on cell viability of VERO cells. Abbreviations: $\alpha$-MMC, alpha-momorcharin; MAP30, momordica anti-HIV protein; PEG, polyethylene glycol; ACV, acyclovir. $\mu \mathrm{mol} \cdot \mathrm{L}^{-1}$. Therefore, the dose range of tested proteins inhibiting VERO cell infection with virus was below $3.3 \mu \mathrm{mol} \cdot \mathrm{L}^{-1}$. The inhibitory effect of $\alpha$-MMC/MAP30, PEGylated $\alpha$-MMC/MAP30, and ACV on HSV-1 glycoprotein antigen secretion glycoprotein was tested through the determination of HSV-1 glycoprotein antigen (Table 3). The results showed a dose-dependent inhibitory effect. $\mathrm{IC}_{50}$ was $0.67 \mu \mathrm{mol} \cdot \mathrm{L}^{-1}$ with $\alpha$-MMC, $2.94 \mu \mathrm{mol} \cdot \mathrm{L}^{-1}$ with PEG- $\alpha-\mathrm{MMC}, 0.47 \mu \mathrm{mol} \cdot \mathrm{L}^{-1}$ with MAP30, $2.39 \mu \mathrm{mol} \cdot \mathrm{L}^{-1}$ with PEG-MAP30, and $3.55 \mu \mathrm{mol} \cdot \mathrm{L}^{-1}$ with $\mathrm{ACV}$, respectively. Furthermore, $\mathrm{IC}_{50}$ of $\alpha-\mathrm{MMC} / \mathrm{MAP} 30$ and PEG- $\alpha-\mathrm{MMC} / \mathrm{MAP} 30$ was lower than the general drug of ACV. At the same dose, the inhibitory effect on HSV-1 glycoprotein antigen secretion, glycoprotein of MAP30 was higher than that of $\alpha$-MMC and PEG-MAP30 was higher than PEG- $\alpha-M M C$. The MTT results showed that the ratio of cell viability can be increased on a dose-dependent feature compared with the control group when protein concentration was higher than $0.03 \mu \mathrm{mol} \cdot \mathrm{L}^{-1}$. But ACV did not display effects on HSV-1 inactivation. At the same dose, the ratio of cell viability with MAP30 was higher than $\alpha$-MMC and PEG-MAP30 was higher than PEG- $\alpha-M M C$. This indicated that both $\alpha$-MMC/MAP30 and PEG- $\alpha-M M C / M A P 30$ had the ability of direct HSV-1 inactivation in a certain range of concentration. Additionally, the effect of inactivation was obvious with the increase of

Table 3 Inhibitory effects of RIPs and PEGylated RIPs on herpes simplex virus-I (HSV-I) antigen

\begin{tabular}{|c|c|c|c|c|}
\hline Protein & Concentration & $\begin{array}{l}\mathrm{OD}_{450} \text { of HSV-I } \\
\text { antigen }\end{array}$ & $\begin{array}{l}\text { Inhibition ratio of } \\
\text { HSV-I antigen (\%) }\end{array}$ & $\begin{array}{l}50 \% \text { inhibiting } \\
\text { concentration }\left(\mu \mathrm{mol}^{-1}\right)\end{array}$ \\
\hline Positive control & $\mu \mathrm{mol} \cdot \mathrm{L}^{-1, *}$ & $0.923 \pm 0.008$ & 0 & \\
\hline Negative control & & $0.004 \pm 0.001$ & & \\
\hline \multirow[t]{4}{*}{$\alpha-M M C$} & 3.3 & $0.270 \pm 0.011$ & 71.055 & 0.67 \\
\hline & 0.3 & $0.550 \pm 0.009$ & 40.588 & \\
\hline & 0.03 & $0.827 \pm 0.003$ & 10.446 & \\
\hline & 0.003 & $0.892 \pm 0.004$ & 3.373 & \\
\hline \multirow[t]{4}{*}{$\alpha$-MMC-PEG } & 3.3 & $0.452 \pm 0.004$ & 51.270 & 2.94 \\
\hline & 0.3 & $0.689 \pm 0.004$ & 25.508 & \\
\hline & 0.03 & $0.866 \pm 0.004$ & 6.241 & \\
\hline & 0.003 & $0.902 \pm 0.003$ & 2.250 & \\
\hline \multirow[t]{4}{*}{ MAP30 } & 3.3 & $0.220 \pm 0.002$ & 76.488 & 0.47 \\
\hline & 0.3 & $0.507 \pm 0.010$ & 45.320 & \\
\hline & 0.03 & $0.807 \pm 0.006$ & $12.59 \mid$ & \\
\hline & 0.003 & $0.890 \pm 0.001$ & 3.556 & \\
\hline \multirow[t]{4}{*}{ MAP30-PEG } & 3.3 & $0.429 \pm 0.003$ & 53.740 & 1.17 \\
\hline & 0.3 & $0.674 \pm 0.004$ & 27.105 & \\
\hline & 0.03 & $0.854 \pm 0.003$ & 7.5472 & \\
\hline & 0.003 & $0.902 \pm 0.000$ & 2.286 & \\
\hline \multirow[t]{4}{*}{ Acyclovir } & 10 & $0.354 \pm 0.004$ & 61.901 & 2.39 \\
\hline & 1 & $0.597 \pm 0.006$ & 35.450 & \\
\hline & 0.1 & $0.872 \pm 0.003$ & 5.515 & \\
\hline & 0.01 & $0.921 \pm 0.006$ & 0.254 & \\
\hline
\end{tabular}

Note: *Compared with positive control $P<0.01$.

Abbreviations: $\alpha-M M C$, alpha-momorcharin; MAP30, momordica anti-HIV protein; PEG, polyethylene glycol. 

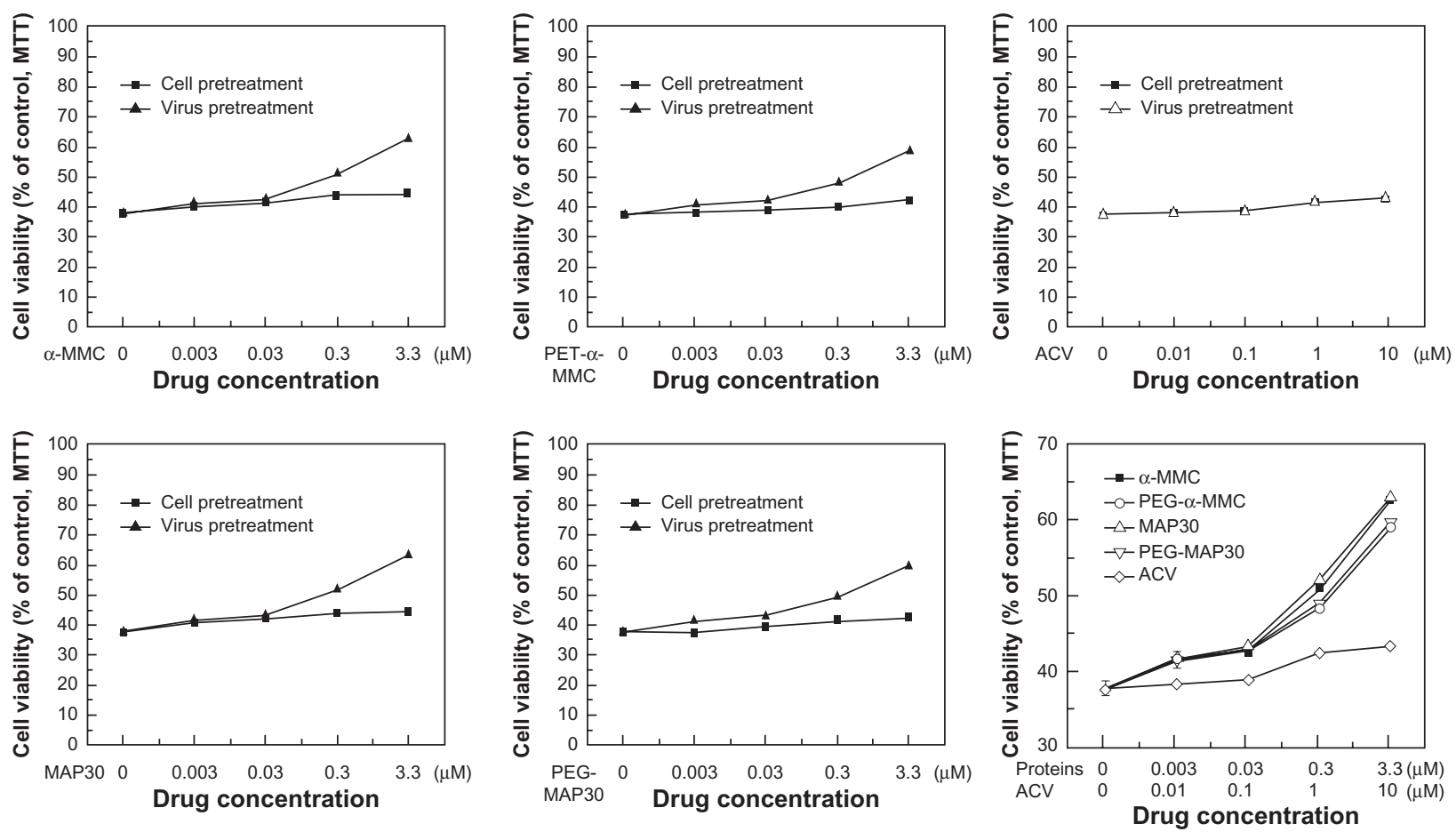

Figure 10 The ratio of cell viability under different concentration of proteins.

protein concentration. VERO cells infected with HSV-1 after 48 hours displayed alterations in the morphology. The inhibitory effect can be observed in groups of $\alpha$-MMC/MAP30, PEG- $\alpha-M M C / M A P 30$, and ACV (Figure 10). The extent of cytopathy was gradually reduced with the increase of the protein concentration. In groups of $\alpha$-MMC and MAP30, most cells did not appear cytopathic caused by virus at a concentration of $3.3 \mu \mathrm{mol} \cdot \mathrm{L}^{-1}$. This indicated that proteins played an important role in the inhibition on HSV-1.

\section{Evaluation of immunogenicity of both PEGylated MAP30 and PEGylated $\alpha-M M C$ in Sprague Dawley rats}

The antigenicity of native and two PEGylated RIPs was evaluated by measuring the specific IgG antibody titers of the serum of Sprague Dasley rats. The results showed that the PEGylated RIPs allowed to some extent decrease of immunogenicity while compared with un-PEGylated counterparts. The decrease of IgG generation was approximately 70\% for PEGylated $\alpha$-MMC compared with the un-PEGylated counterpart and 50\% for PEGylated MAP30 compared with the un-PEGylated counterpart.

\section{Conclusion}

A novel preparative strategy of both $\alpha$-MMC and MAP30 at one time was successfully established. Some properties of these proteins were assessed by SDS-PAGE, ESI-QUAD-MS, MALDI-TOF-MS, and $N$-terminal sequence as well as Western blotting. This fast, highly efficient methodology enables us to focus more energy on subsequent research. A branched (mPEG) $)_{2}$-Lys-NHS(20 kDa) was used to modify these proteins and the serial PEGylated ones were assessed by gradient SDS-PAGE and MALDI-TOF-MS. The $\alpha-M M C$ modifier possessed one-mer, two-mer, and three-mer PEGbound chains, while MAP30 modifier obtained one-mer and two-mer PEG-bound chains. PEGylated conjugates preserved moderate activities on JAR choriocarcinoma cells and HSV-1. Furthermore, both PEGylated proteins showed about $60 \%-70 \%$ antitumor and antivirus activities as well as a $50 \%-70 \%$ immunogenicity decrease when compared with unmodified counterparts. To sum up, PEGylation of $\alpha$-MMC and MAP30 may offer a possible way for their clinical application as potential therapeutic agents. Nevertheless, to fulfill the requirements of a useful drug, we should meet the challenges, including the reduction of immunogenicity to the greatest extent, the retention of sufficient activity, the extension of the half-life period, and development of various forms of PEG-RIPs. This work is just the beginning for them to be used clinically. After all, therapeutic proteins must fulfill the requirements described previously. PEGylation can reduce immunogenicity and retain certain biological activity of RIPs, but there is lots of work to do for further decreasing their immunogenicity and extending the half-life period. 
Future work concerns packing RIPs with nanomaterials for targeting drugs and low release.

\section{Acknowledgments}

This work was supported by the National Science Foundation of China (Grant No 30770232).

\section{Disclosure}

The authors report no conflicts of interest in this work.

\section{References}

1. Read BE, Liu J, Li S. (1956) Pen ts'ao kang mu [Chinese pharmaceutical compendium]. Beijing, China: People's Medical Publishing House; 1977.

2. Stirpe F. Ribosome-inactivating proteins. Toxicon. 2004;44(4): 371-383.

3. Hausner TP, Atmadja J, Nierhaus KH. Evidence that the G2661 region of $23 \mathrm{~S}$ rRNA is located at the ribosomal binding sites of both elongation factors. Biochimie. 1987;69(9):911-923.

4. Bourinbaiar AS, Lee-Huang S. The activity of plant-derived antiretroviral proteins MAP30 and GAP31 against herpes simplex virus in vitro. Biochem Biophys Res Commun. 1996;219(3):923-929.

5. Foà-Tomasi L, Campadelli-Fiume G, Barbieri L, Stirpe F. Effect of ribosome-inactivating proteins on virus-infected cells. Inhibition of virus multiplication and of protein synthesis. Arch Virol. 1982;71(4): 323-332.

6. McGrath MS, Hwang KM, Caldwell SE, et al. GLQ223: an inhibitor of human immunodeficiency virus replication in acutely and chronically infected cells of lymphocyteand mononuclea phagocyte lineage. Proc Natl Acad Sci U SA. 1989;86(8):2844-2848.

7. Huang PL, Sun Y, Chen HC, Kung HF, Lee-Huang S. Proteolytic fragments of anti-HIV and anti-tumor proteins MAP30 and GAP31 are biologically active. Biochem Biophys Res Commun. 1999;262(3):615-623.
8. Kozlowski A, Harris JM. Improvements in protein PEGylation: pegylated interferons for treatment of hepatitis C. $J$ Control Release. 2001;72(1-3):217-224.

9. Harris JM, Chess RB. Effect of pegylation on pharmaceuticals. Nat Rev Drug Discov. 2003;2(3):214-221.

10. Roberts MJ, Bentley MD, Harris JM. Chemistry for peptide and protein PEGylation. Adv Drug Deliv Rev. 2002;54(4):459-476.

11. Lord JM, Hartley MR, Roberts LM. Ribosome inactivating proteins of plants. Semin Cell Biol. 1991;2(1):15-22.

12. Lee-Huang S, Huang PL, Chen HC, et al. Anti-HIV and anti-tumor activities of recombinant MAP30 from bitter melon. Gene. 1995; 161(2):151-156.

13. Lee-Huang S, Huang PL, Nara PL, et al. MAP30: a new inhibitor of HIV-1 infection and replication. FEBS Lett. 1990;272(1-2):12-18.

14. Lowry OH, Rosebrough NJ, Farr AL, Randall RJ. Protein measurement with the Folin phenol reagent. J Biol Chem. 1951;193(1):265-275.

15. Laemmli UK. Cleavage of structural proteins during the assembly of the head of bacteriophage T4. Nature. 1970;227(5259):680-685.

16. Ng TB, Shaw PC, Yeung HW, Ho WK. Immunological relatedness of ribosome-inactivating proteins from the Cucurbitaceae family. Biochem Mol Biol Int. 1993;31(3):447-453.

17. Lee-Huang S, Huang PL, Sun Y, et al. Lysozyme and RNases as anti-HIV components in beta-core preparations of human chorionic gonadotropin. Proc Natl Acad Sci U S A. 1999;96(6):2678-2681.

18. Li M, Chen Y, Liu Z, Shen F, Bian X, Meng Y. Anti-tumor activity and immunological modification of ribosome-inactivating protein (RIP) from Momordica charantia bycovalent attachment of polyethylene glycol. Acta Biochim Biophys Sin (Shanghai). 2009;41(9):792-799.

19. Reed L, Muench H. A simple method of estimating fifty per cent endpoints. Am J Epidemiol. 1938;27(3):493.

20. Yang ZY, Kong WP, Huang Y, et al. A DNA vaccine induces SARS coronavirus neutralization and protective immunity in mice. Nature. 2004;428(6982):561-564

21. Mosmann T. Rapid colorimetric assay for cellular growth and survival: application to proliferation and cytotoxicity assays. J Immunol Methods. 1983;65(1-2):55-63.

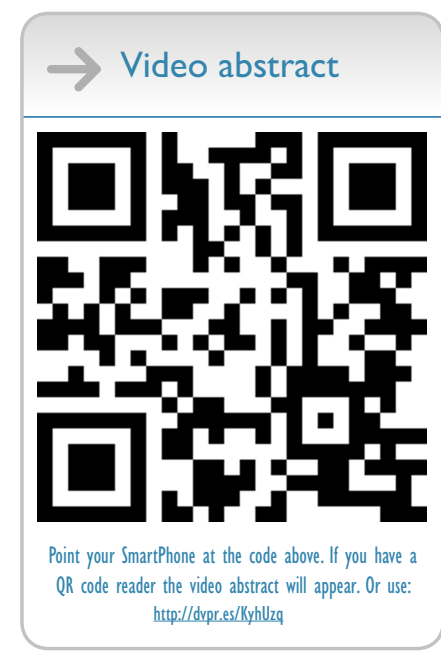

International Journal of Nanomedicine

\section{Publish your work in this journal}

The International Journal of Nanomedicine is an international, peerreviewed journal focusing on the application of nanotechnology in diagnostics, therapeutics, and drug delivery systems throughout the biomedical field. This journal is indexed on PubMed Central, MedLine, CAS, SciSearch ${ }^{\circledR}$, Current Contents ${ }^{\circledR} /$ Clinical Medicine,

\section{Dovepress}

Journal Citation Reports/Science Edition, EMBase, Scopus and the Elsevier Bibliographic databases. The manuscript management system is completely online and includes a very quick and fair peer-review system, which is all easy to use. Visit http://www.dovepress.com/ testimonials.php to read real quotes from published authors. 